\title{
WHITE SPOTTING IN THE CALIFORNIA VOLE
}

\author{
AYESHA E. GILL \\ Museum of Vertebrate Zoology and Department of Genetics, University of California, Berkeley 94720 , \\ and Department of Biology, University of California, Los Angeles 90024*
}

Received 24.i.76.

\begin{abstract}
SUMmARY
Previously unreported white spotting was found in two subspecies of the California vole, Microtus californicus. The pattern of spots on the ventral coat of the animals differs between the subspecies, and there is variation in the expressivity of the white spots. Expression of white spotting is greatly reduced by the epistatic action of another coat colour gene, the recessive buffy $(b f)$. The incidence of white spotting, its variation in expression, and its inheritance were investigated in this study. The reproductive performance of white spotted voles was also analysed, and effects on fertility and litter size were found associated with the trait.
\end{abstract}

\section{INTRODUCTION}

ONLY a few cases of polymorphism have been reported for the California vole, Microtus californicus. One that has been well documented is the agouti-buffy coat-colour polymorphism discovered in the population of California voles on Brooks Island in San Francisco Bay (Lidicker, 1963; Gill, 1972). Now, a second polymorphism, previously unreported for this species, has been detected in the same population. I observed white spotting in some of the Brooks Island voles and found the trait to be heritable. Individuals from two mainland populations of the same subspecies (M. c. californicus) in the San Francisco Bay area also carry white spotting genes, and a variation of the trait is found in a mainland population of another subspecies, M. c. stephensi, in Los Angeles County. The trait probably occurs in other populations that have not been investigated.

White spotting occurs widely in mammalian populations (Searle, 1968), and its inheritance has been best studied in the house mouse (Deol, 1970). Stoddard (1970) reported on the incidence of three partial "albinisms" in voles of the genus Arvicola. One of these was white-spotting of the throat, which he found to occur at an incidence of 20 per cent in museum specimens from Britain and Eurasia. The mechanism of inheritance was not investigated. Much less is known about white spotting or other coat colour variations in Microtus, and breeding data are scarce (Little, 1958; Robinson, 1970). Owen and Shackelford (1942) list two white spotted M. pennsylvanicus specimens and one $M$. californicus skin with a small white spot just dorsal to and behind the right foreleg. They noted the possibility that the spot was the result of injury.

The study of coat colour variation in mammals has long received attention and remains important in the investigation of evolutionary relationships and developmental processes (Searle, 1968; review articles in Berry and Southern,

* Present address 
1970; Quevedo, 1971). Data are available on variation in a wide range of mammals, most of the detailed genetic studies being on standard laboratory or domestic animals. There is a need for data on polymorphisms in natural populations of the less well-studied mammals. In order to be of value in comparative mammalian studies, these should include detailed descriptions of the coat colour trait and/or the mode of inheritance (Robinson, 1970).

This paper fully describes the phenotypic expression of white spotting in two subspecies of the California vole and reports the investigation of possible pleiotropic effects relating to reproduction. As Little (1958) points out, the genetic basis of white spotting is one of the most difficult to analyse. That holds true for this case also. The trait is variable in expression and does not have a simple Mendelian inheritance pattern. The results of studies of inheritance in the two subspecies are reported.

\section{MAterials AND METHODS}

I first noticed patches of white hair on the chins of voles of the subspecies Microtus californicus californicus live-trapped on Brooks Island in San Francisco Bay. The island population is polymorphic for coat colour (Lidicker, 1963; Gill, 1972), some of the voles being agouti $(+/+$ and $+/ b f)$ and others buffy $(b f / b f)$. In contrast to the grizzled agouti phenotype, the buffy pelage is smooth, non-grizzled, and light grey-brown in colour. White spotting is obvious against either coat colour. A laboratory colony was established from the Brooks Island voles, initially to study the agouti-buffy polymorphism and subsequently the white-spotting as well. The colony was infused with additional individuals from the island and one sample from the California mainland over a 20 -month period.

The incidence and expressivity of white spots in the captured animals and members of the laboratory colony were recorded. M. c. californicus specimens collected by W. Z. Lidicker, Jr. and maintained in the Museum of Vertebrate Zoology at the University of California, Berkeley, were also examined for white spots.

Using voles of the californicus subspecies from Brooks Island and Berkeley and the stephensi subspecies from the Santa Monica Mountains, Los Angeles County, I established a second laboratory colony at the University of California, Los Angeles. The incidence and pattern of white spotting in intrasubspecific and intersubspecific crosses were studied. The stephensi and their hybrids have white spots on the chest in addition to the chin spots.

Crosses between white-spotted animals were set up in both colonies to investigate the inheritance of the trait and to detect any effect on productivity associated with it.

\section{RESULtS}

(i) Incidence of white spotting

The incidence of white chin spots in agouti Microtus californicus californicus trapped on Brooks Island is 7.6 per cent (table 1). Presence of a buffy allele $(b f)$ reduces the incidence of white chin spots (tables 1 and 2). Because heterozygotes for $b f$ are indistinguishable in coat colour from homozygous agoutis, only those which were progeny-tested or of known heterozygous genotype from specific laboratory crosses are designated as heterozygotes $(\mathbf{H})$. 
TABLE 1

Incidence of the white chin spot trait $(\mathrm{w})$ in M. c. californicus laboratory voles and samples from Brooks Island and Orinda

Pelage phenotype and genotype of offspring

\begin{tabular}{|c|c|c|c|c|c|c|c|c|c|c|c|}
\hline \multirow[b]{2}{*}{$\begin{array}{c}\text { Parental } \\
\text { chin types }\end{array}$} & \multirow[b]{2}{*}{$\begin{array}{c}\text { Birth } \\
\text { place* }^{*}\end{array}$} & \multirow[b]{2}{*}{ Sex } & \multicolumn{3}{|c|}{$\begin{array}{l}\text { Agouti (A) } \\
+/+ \text { or }+/ b f\end{array}$} & \multicolumn{3}{|c|}{$\begin{array}{c}\text { Buffy (B) } \\
\quad b f / b f\end{array}$} & \multicolumn{3}{|c|}{$\begin{array}{l}\text { Agouti }(\mathrm{H}) \\
+/ b f \text { only }\end{array}$} \\
\hline & & & Non- $w$ & $w$ & $\% w$ & Non-w & $w$ & $\% w$ & Non-w & $w$ & $\% w$ \\
\hline $\begin{array}{l}\text { Neither } w \\
\text { Neither } w\end{array}$ & $\begin{array}{l}\text { Lab. } \\
\text { Lab. }\end{array}$ & $\begin{array}{l}\text { + } \\
\sigma\end{array}$ & $\begin{array}{l}548 \\
561\end{array}$ & $\begin{array}{l}36 \\
26\end{array}$ & $\begin{array}{l}6 \cdot 2 \\
4 \cdot 4\end{array}$ & $\begin{array}{l}306 \\
332\end{array}$ & $\begin{array}{l}4 \\
5\end{array}$ & $\begin{array}{l}1 \cdot 3 \\
1 \cdot 5\end{array}$ & $\begin{array}{l}538 \\
596\end{array}$ & $\begin{array}{r}13 \\
8\end{array}$ & $\begin{array}{l}2 \cdot 4 \\
1 \cdot 3\end{array}$ \\
\hline $\begin{array}{l}\text { One } w \\
\text { One } w\end{array}$ & $\begin{array}{l}\text { Lab. } \\
\text { Lab. }\end{array}$ & $\begin{array}{l}q \\
\sigma\end{array}$ & $\begin{array}{l}95 \\
95\end{array}$ & $\begin{array}{l}70 \\
60\end{array}$ & $\begin{array}{l}42 \cdot 9 \\
38 \cdot 7\end{array}$ & $\begin{array}{l}1 \\
3\end{array}$ & $\begin{array}{l}1 \\
1\end{array}$ & $\begin{array}{l}50 \cdot 0 \\
25 \cdot 0\end{array}$ & $\begin{array}{l}80 \\
83\end{array}$ & $\begin{array}{l}6 \\
9\end{array}$ & $\begin{array}{l}7 \cdot 0 \\
9 \cdot 8\end{array}$ \\
\hline $\begin{array}{l}\text { Both } w \\
\text { Both } w\end{array}$ & $\begin{array}{l}\text { Lab. } \\
\text { Lab. }\end{array}$ & $\begin{array}{l}q \\
\sigma\end{array}$ & $\begin{array}{l}68 \\
69\end{array}$ & $\begin{array}{l}81 \\
91\end{array}$ & $\begin{array}{l}54 \cdot 4 \\
56 \cdot 9\end{array}$ & $\begin{array}{l}3 \\
4\end{array}$ & $\begin{array}{l}2 \\
1\end{array}$ & $\begin{array}{l}40 \cdot 0 \\
20 \cdot 0\end{array}$ & $\begin{array}{l}23 \\
24\end{array}$ & $\begin{array}{l}7 \\
7\end{array}$ & $\begin{array}{l}23 \cdot 3 \\
22 \cdot 6\end{array}$ \\
\hline $\begin{array}{l}\text { Unknown } \\
\text { Unknown }\end{array}$ & $\begin{array}{l}\mathrm{BI} \dagger \\
\mathrm{BI} \dagger\end{array}$ & $\begin{array}{l}\text { o } \\
\sigma\end{array}$ & $\begin{array}{l}175 \\
178\end{array}$ & $\begin{array}{l}14 \\
15\end{array}$ & $\begin{array}{l}7 \cdot 4 \\
7 \cdot 8\end{array}$ & $\begin{array}{l}3 \\
5\end{array}$ & $\begin{array}{l}0 \\
0\end{array}$ & $\begin{array}{l}0 \\
0\end{array}$ & $\begin{array}{l}4 \\
7\end{array}$ & $\begin{array}{l}0 \\
0\end{array}$ & $\begin{array}{l}0 \\
0\end{array}$ \\
\hline $\begin{array}{l}\text { Unknown } \\
\text { Unknown }\end{array}$ & $\begin{array}{l}\text { Or. } \ddagger \\
\text { Or. } \ddagger\end{array}$ & $\begin{array}{l}\text { 웅 } \\
\sigma\end{array}$ & $\begin{array}{r}6 \\
13\end{array}$ & $\begin{array}{l}1 \\
0\end{array}$ & $\begin{array}{c}14 \cdot 3 \\
0\end{array}$ & & & & 1 & 0 & 0 \\
\hline
\end{tabular}

* Lab.: laboratory; BI : Brooks Island; Or.: Orinda.

† Data from 14 samples trapped between March 1959 and March 1971 on Brooks Island by W. Z. Lidicker, Jr. and 5 samples trapped between March 1969 and March 1971 for the laboratory.

$\mp$ Data from one sample trapped in Orinda in October 1970. There were no buffies.

TABLE 2

Percentage of offspring with white chin spots in all types of laboratory crosses of M. c. californicus

\begin{tabular}{|c|c|c|c|c|}
\hline \multirow{2}{*}{$\begin{array}{l}\text { Parental } \\
\text { type* }\end{array}$} & \multirow{2}{*}{$\begin{array}{l}\text { Number of } \\
\text { offspring } \\
\text { weaned }\end{array}$} & \multicolumn{2}{|c|}{$\begin{array}{c}\text { Number } \\
\text { white-spotted }\end{array}$} & \multirow{2}{*}{$\begin{array}{c}\text { Percentage } \\
\text { white-spotted }\end{array}$} \\
\hline & & q & o & \\
\hline $\mathrm{A}$ 우 $\times \mathrm{A}^{\vec{\sigma}}$ & 529 & 24 & 17 & $7 \cdot 8$ \\
\hline $\mathrm{A}+{ }^{\prime} \times \mathrm{B}^{\top}$ & 410 & 4 & 4 & $2 \cdot 0$ \\
\hline $\mathrm{A}$ 우 $\times \mathrm{H}_{0}$ & 148 & 1 & 4 & $3 \cdot 4$ \\
\hline $\mathrm{B}$ 우 $\times \mathrm{B}^{\hat{0}}$ & 228 & 4 & 3 & $3 \cdot 2$ \\
\hline $\mathrm{B}+\times \mathbf{A}_{\sigma}^{\top}$ & 368 & 0 & 0 & 0 \\
\hline $\mathrm{B} q \times \mathrm{H}_{\sigma}^{*}$ & 281 & 3 & 2 & $1 \cdot 8$ \\
\hline $\mathrm{H}_{+} \times \mathrm{H}^{\star}$ & 508 & 2 & 2 & $0 \cdot 8$ \\
\hline $\mathrm{H}$ 우 $\times \mathrm{A}_{\sigma}$ & 80 & 4 & 0 & $5 \cdot 0$ \\
\hline $\mathrm{H}^{\prime}+\mathrm{B}^{\top}$ & 223 & 2 & 0 & 0.9 \\
\hline $\mathrm{A}+9 \times \mathrm{A}^{w} \sigma^{\pi}$ & 122 & 25 & 25 & $41 \cdot 0$ \\
\hline $\mathrm{A}^{w}+\times \mathrm{A}_{\sigma}^{\top}$ & 181 & 42 & 25 & $37 \cdot 0$ \\
\hline $\mathbf{A}^{w}+\propto \mathbf{A}^{w} \sigma^{*}$ & 184 & 63 & 59 & $66 \cdot 3$ \\
\hline $\mathrm{A}^{w} \phi \times \mathrm{B}^{*}$ & 108 & 4 & 6 & $9 \cdot 7$ \\
\hline
\end{tabular}

* A: wildtype agouti $(+/+)$; B: buffy $(b f / b f) ; \mathbf{H}$ : heterozygote $(+/ b f)$. The $w$ superscript stands for presence of a white chin spot. 


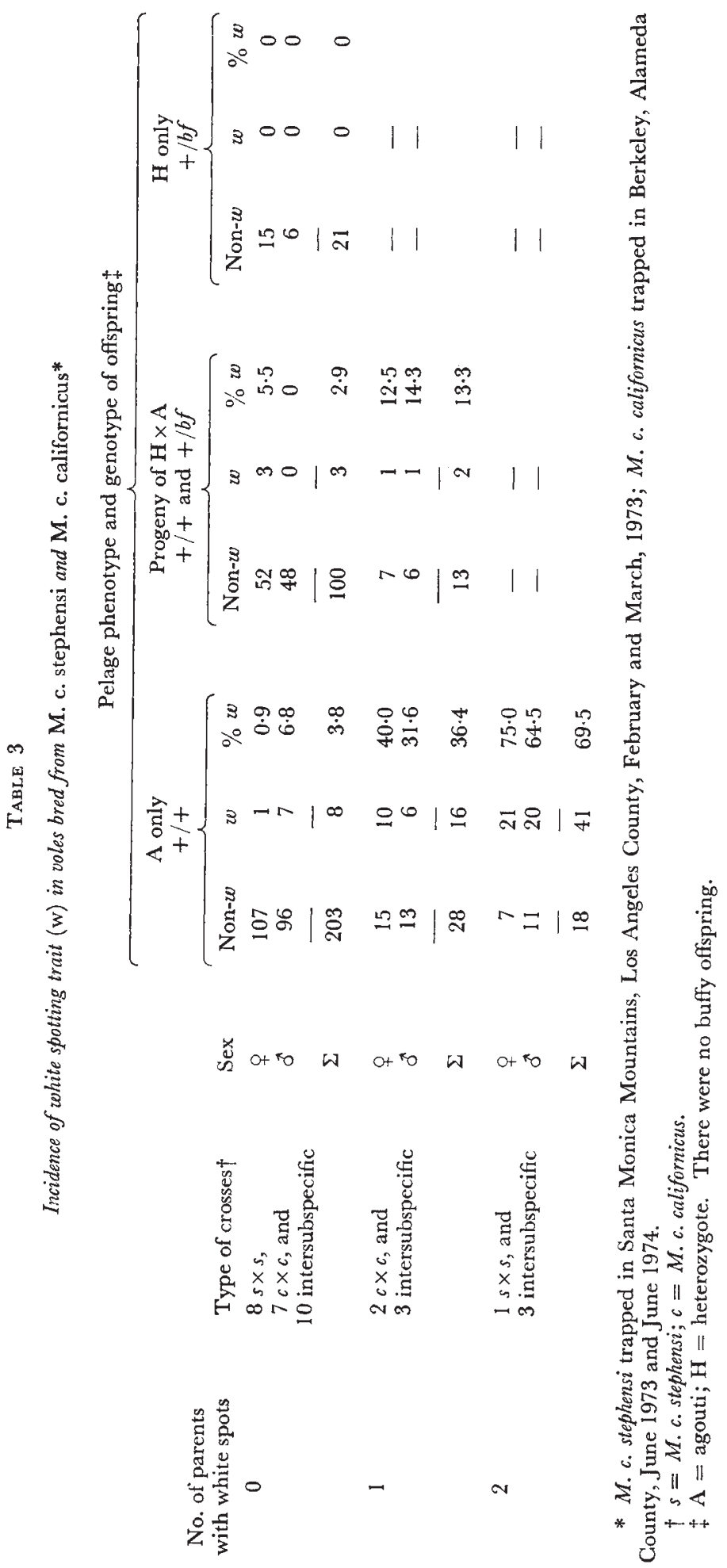


Incidence of the white chin spot trait is significantly lower $(P=0.001)$ for known heterozygotes than for other agouti voles, not only in the offspring from non-spotted parents but also from crosses in which one or both parents are spotted (table 1). Buffy voles also have a significantly lower incidence of the trait than the homozygous agouti voles $(P=0.001)$. Thus, the white chin spot trait is differentially associated with homozygous agouti voles.

There is a dramatic increase in the incidence of white chin spots among the offspring of parents with the trait (tables 1 and 2). It is especially high if both parents have white chin spots. The frequency of white-spotting in Brooks Island-trapped voles is a little higher than that of laboratory voles born to unspotted parents but much lower than that of offspring from spotted parents. Most of the white-spotted voles trapped in the field probably came from matings in which neither parent exhibited the trait, or, at most, one.

The great majority of voles analysed in tables 1 and 2 were trapped on Brooks Island or were the descendants of island voles. The Orinda sample of 20 was from the California mainland, Contra Costa County, and one of these had a white chin spot. An additional 28 voles of the californicus subspecies were trapped in Berkeley, Alameda County, in 1973 and 1974. One of these had a white chin spot but died before being mated, so he did not contribute any white-spotting genes to the colony. Nine of the Berkeley voles were bred in the laboratory and six produced white-spotted descendants in the $\mathbf{F}_{1}$ or $\mathbf{F}_{2}$ generation. Similarly, of 14 voles of the stephensi subspecies trapped in the Santa Monica Mountains, none had white spots, but whitespotting showed up among the $\mathrm{F}_{1}$ and $\mathrm{F}_{2}$ progeny of 10 of them. Thus, none of the progenitors of the UCLA laboratory colony exhibited a whitespotting trait, but it occurred spontaneously among their descendants and was easily selected for (table 3 ).

Once the white-spotting trait appears in a family, it is generally maintained in subsequent generations in the laboratory. All fertile crosses involving a white-spotted individual in the UCLA laboratory colony produced some white-spotted offspring. Of 46 crosses involving a white-spotted vole in the Berkeley colony, only six did not produce any spotted offspring, and four of these were crosses between a spotted agouti and a buffy $\left(A^{w} \times B\right)$. The remaining two crosses, between agoutis, only produced one litter each, not enough to ascertain the presence or absence of the trait.

It is clear that genes for white-spotting occur in the mainland populations of $M$. c. californicus and stephensi, as well as the island population of californicus. The mainland sample sizes were not comparable with the larger island samples, and only two white-spotted individuals were trapped on the mainland. The Berkeley and Santa Monica populations possessed a large store of hidden variability, however, and the trait was prevalent among their laboratory-born offspring. There may be some selection against the whitespotting trait in mainland populations. Broader sampling would be useful to study this question.

\section{(ii) Specificity and expressivity of white-spotting genes}

White spotting is specific to the chin in $M$. c. californicus, and it is of variable expression (fig. 1). The following size categories were defined for the expression of the white hair patches on the chin: 
0 none,

1 barely noticeable,

3 distinct, but of moderate size,

5 very large.
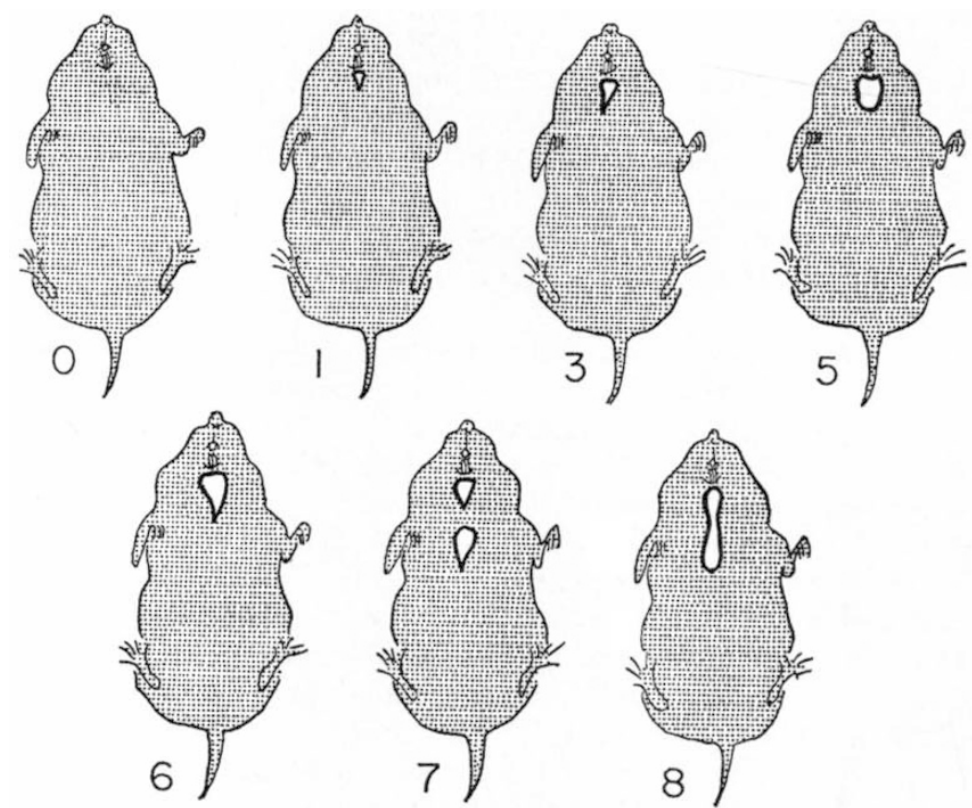

FIg. 1.-Variation in white spotting in Microtus californicus. Spots 1 through 5 occur in M. c. californicus, 1 through 8 in M.c. stephensi and hybrids.

Most of the chin spots fell into category 3, only the extreme cases being classified as 1 or 5 . In addition to chin spots, $M$. c. stephensi and its hybrids sometimes have white hair spots on the chest. Their spotting patterns are described by categories 1 through 5 and these additional ones:

6 extension of the chin spot a short distance on to the neck,

7 disjunct spots on the chin and chest,

8 continuous white patch from chin to chest.

None of the voles ever exhibits a white spot on the chest when there is none on the chin.

The size of the progeny's white spots tends to increase if their parents have large spots or if both parents are spotted (fig. 2). The only offspring departing noticeably from this trend are the $M$. c. stephensi and hybrid group born to parents with spot sizes 3 and 7 . The departure may be due to the small sample size in this case $(n=7)$.

If the parents are not spotted, their spotted offspring tend to fall in the smaller size categories. Thus, only 4 of the 1042 californicus offspring from unspotted parents had size 5 spots, and no stephensi or hybrid offspring with size 7 or 8 spots were produced by non-spotted parents.

The epistatic partial suppression of white spotting by the buffy allele is evident in fig. 2. If one or both of the parents are buffs or heterozygotes, 
only a small fraction of their progeny are white-spotted. The fraction of progeny exhibiting the trait does increase with the incidence and expressivity of the trait in the parents, however, just as it does in the homozygous agouti crosses.
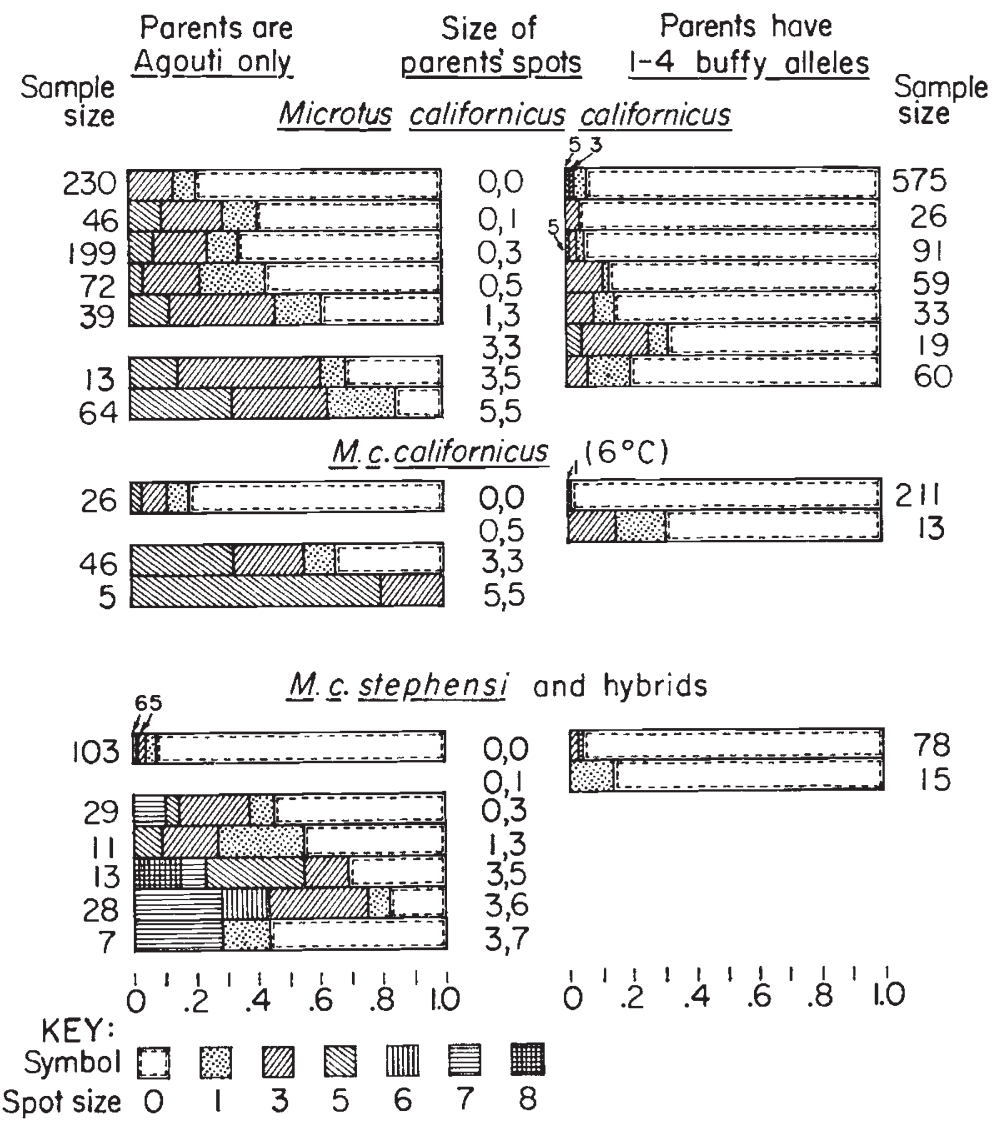

FIG. 2.-Fraction of offspring of each white spot size from families with varying expressions of spotting. Offspring of parents with and without buffy alleles are contrasted. Some $M$. c. californicus were bred at $6^{\circ} \mathrm{C}$; their offspring are grouped separately. All other crosses were at ambient temperatures. M. c. stephensi $\times$ M. c. californicus hybrids exhibited the same range of spots as $M$. c. stephensi and are grouped with the latter.

(iii) Inheritance of the trait

It is obvious from the data that white spotting is a heritable trait in Microtus californicus. The mode of inheritance is not as obvious. The progeny classes do not follow regular Mendelian segregation ratios, and it is very difficult in such cases to find the genetic basis of the trait. The fraction of offspring not showing the white-spotting trait is large in most families and remains sizeable even in crosses in which both parents are spotted, unless the parents have very large spots (fig. 2). This suggests there may be a threshold for the expression of the trait. 
Falconer (1965) developed a multifactorial threshold model of a trait based on a continuous liability distribution, but expressed only at a threshold and thus appearing as an all-or-none classification. He showed that the method developed in quantitative genetics to analyse threshold characters (Falconer, 1960) could be applied to the inheritance of liability to certain illnesses for which the incidences in the general population and in relatives of the affected are known. My data on the white-spotting trait take an analogous form and are amenable to such analysis. The correlations between relatives is simply calculated from the incidence among relatives of an affected individual and the incidence in the general population. The data were analysed by means of a computer program based on an extension of Falconer's model. Reich et al. (1972) used multiple thresholds to analyse the mode of inheritance of semi-continuous traits, i.e. traits ungraded in the unaffected part of the population but divisible into milder or more severe forms in the affected individuals. In their models a threshold is set for the expression of the trait and an additional threshold stated for the expression of more severe forms of the trait. Three categories result: unaffected (corresponding to my 0 spot size category), affected but not severely (spot sizes 1 and 3 ), severely affected (spot sizes 5, 6, 7 and 8). The use of two thresholds gives sufficient information to test the goodness of fit of the models to the data. Reich et al. (1972) developed two threshold models that can be tested in this way: a single-locus two-allele model with incomplete penetrance and dominance, and a model of additive polygenic inheritance.

Data from 16 affected families, involving 32 parents and 292 offspring in the Berkeley colony were analysed, and a separate test of the data from 14 affected families involving 28 parents and 207 offspring in the UCLA colony was made. Both models were rejected according to the tests. No reassignment of threshold levels could cause the models to fit the data reasonably. The computer analysis indicated that penetrance is complete for the trait, that a single gene-two allele system with dominance does not fit the data, and that an additive multifactorial system of inheritance does not fit it either.

A variant of the models described above that sets separate thresholds for the sexes (K. K. Kidd, T. Reich and S. Kessler, unpublished) was also tested with a computer program. The single gene model was again emphatically rejected, showing that consideration of a sex effect on the trait does not provide a more suitable model. Hand calculations were made to analyse the possibility of inheritance through a single gene with multiple alleles, analogous to the A series of alleles at the agouti locus in rodents (Searle, 1968). The single gene-multiple allele model does not appear applicable either. The fraction of unaffected siblings of spotted individuals born to unaffected parents is too large. In families in which the parents are spotted the range of spot sizes and patterns of the offspring are too great to be accounted for by a single locus, even with multiple alleles.

A single major gene with two alleles, a major gene with threshold and dominance, additive polygenic inheritance with a threshold, a single gene with threshold differences between the sexes and a single locus with multiple alleles can therefore all be rejected as the means of inheritance of this trait. The trait has been shown to be completely penetrant, and the data indicate a threshold for its expression. The most reasonable assumption appears to be that the inheritance is a non-additive polygenic system with a threshold 
and important gene interactions, possibly both epistatic interactions and dominance at some loci.

An epistatic interaction with the buffy locus is also indicated by the fact that in voles carrying one or two buffy alleles the expression of the trait is severely diminished.

\section{(iv) Reproductive performance of white-spotted voles}

A study of the reproductive performance of white-spotted voles was conducted in the Berkeley colony of $M$. c. californicus to explore the possibility of an effect on reproductive fitness associated with the white-spotting trait. Data on unspotted voles are available for comparison (Gill, 1972). Fifty-four crosses between wildtype agoutis in which one or both parents had white spots and 12 crosses between spotted agouti females and buffy males were set up (table 4). Due to a shortage of spotted agouti males, no reciprocal crosses of the type $\mathrm{B} \times \mathrm{A}^{w}$ were arranged. The pair in each cross was placed together in a metal cage $\left(30 \times 47 \mathrm{~cm}^{2}\right.$ base with sloping sides, $15 \mathrm{~cm}$ front and $20 \mathrm{~cm}$ back) and remained together throughout the study. Maintenance of the laboratory crosses is described in detail in Gill (1972).

TABle 4

Reproductive data on crosses of voles with white chin spots

\begin{tabular}{|c|c|c|c|c|c|c|c|}
\hline $\begin{array}{l}\text { Parental } \\
\text { type }\end{array}$ & $\begin{array}{l}\text { No. of } \\
\text { fertile } \\
\text { crosses }\end{array}$ & $\begin{array}{l}\text { No. not } \\
\text { fertile }\end{array}$ & $\begin{array}{l}\text { No. of } \\
\text { offspring } \\
\text { born }\end{array}$ & $\begin{array}{l}\text { Percentage } \\
\text { weaned }\end{array}$ & $\bar{P}_{B} *$ & $\tilde{P}_{W} \dagger$ & $\begin{array}{c}\text { Mean } \\
\text { litter } \\
\text { size }\end{array}$ \\
\hline $\mathbf{A} q \times \mathrm{A}^{w} \sigma^{\star}$ & 8 & 1 & 138 & $88 \cdot 4$ & $3 \cdot 86$ & $3 \cdot 56$ & $4 \cdot 73$ \\
\hline $\mathbf{A}^{w} q \times \mathbf{A}_{\sigma^{\lambda}}$ & 11 & 1 & 215 & $84 \cdot 1$ & 3.08 & $2 \cdot 71$ & $3 \cdot 78$ \\
\hline $\mathbf{A}^{w} q \times \mathbf{A}^{w} \sigma^{*}$ & 17 & 16 & 220 & $83 \cdot 6$ & $3 \cdot 16$ & $2 \cdot 62$ & $4 \cdot 30$ \\
\hline $\mathrm{A}^{w}+\times \mathrm{B}_{0}^{\lambda}$ & 10 & 2 & 123 & $87 \cdot 8$ & $2 \cdot 92$ & $2 \cdot 60$ & $3 \cdot 44$ \\
\hline \multicolumn{8}{|c|}{ For comparison, the data for analogous non-spotted crosses are + : } \\
\hline $\mathrm{A}+\mathrm{P}_{\mathrm{O}} \mathrm{A}_{0}^{-1}$ & 35 & 16 & 470 & $90 \cdot 6$ & $3 \cdot 27$ & $2 \cdot 96$ & $4 \cdot 21$ \\
\hline $\mathrm{A}+\mathrm{B}_{0}$ & 31 & 14 & 435 & $94 \cdot 0$ & $2 \cdot 98$ & $2 \cdot 80$ & $4 \cdot 20$ \\
\hline
\end{tabular}

Striking differences occur in the percentage of fertile crosses among various parental combinations of spotted and non-spotted voles (table 4). The crosses in which only one of the parents has a white chin spot have the highest percentage of fertile crosses (an average of 87.9 per cent), the nonspotted crosses are next ( 69.8 per cent), and the crosses in which both parents are spotted have the lowest fertility (51.5 per cent). These differences are significant at the 0.01 level (chi-square test of homogeneity). Thus, if only one member of the cross has the white spot trait, the fertility of the mating is enhanced, but if both have the trait there seems to be a negative interaction between the pair reducing fertility.

Crosses in which both parents had white chin spots were almost equally divided between fertile and unproductive matings (17 and 16, respectively). There appears to be no relationship between the size of the parents' spots and their fertility (fig. 3). There were 17 crosses set up of parents with spot sizes 1,1 to 3,3 and 16 of parents 3,5 to 5,5 . The median in distributions of both fertile and unproductive matings was between 3,3 and 3,5 . Thus, the 
presence of the trait in both parents, not the degree of its expression, reduces fertility.

Comparisons of the mean number of offspring both per 30 days $\left(\overline{\mathrm{P}}_{\mathrm{B}}\right)$ and weaned per 30 days $\left(\overline{\mathrm{P}}_{\mathrm{W}}\right)$ were made among fertile crosses of the four parental types, using the non-parametric Kruskal-Wallis test (Sokal and Rohlf, 1969). The differences in productivity among the crosses were not significant. It should be noted, however, that crosses in which the female was whitespotted all had lower mean productivities than those in which the female was unspotted and the male possessed the trait (table 4). The crosses in which white-spotted parents were involved were also compared with analogous non-spotted crosses, and no significant differences in productivity were found (Wilcoxon test, Sokal and Rohlf, 1969).

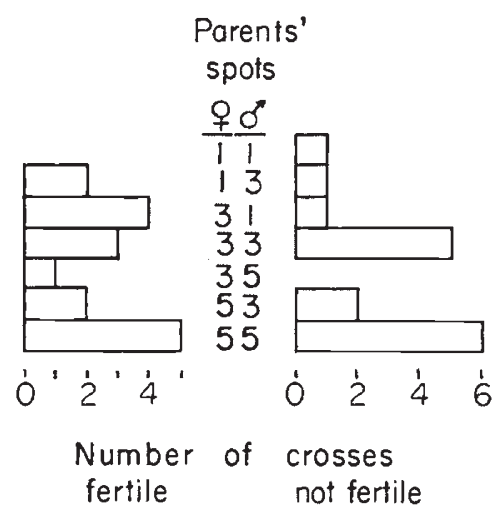

FIG. 3.-Number of fertile and non-fertile crosses between parents of various spot sizes.

To see if there was any detectable effect of chin spot size on productivity, the crosses were divided into groups according to the size of the parents' spots, and the mean productivity values $\left(\overline{\mathrm{P}}_{\mathrm{B}}\right.$ and $\left.\mathrm{P}_{\mathrm{W}}\right)$ for the groups were compared using the Kruskal-Wallis test. No significant differences were found.

The differences in mean litter size among the spotted families are not significant (Kruskal-Wallis test), although non-spotted females had a higher mean litter size than spotted females, which is reflected in their higher productivity values (table 4). There is a great deal of variation in the size of litters produced by Microtus californicus, even within crosses of the same type (table 5). The variation shown for the white-spotted crosses is also characteristic of non-spotted crosses (Gill, 1972). Despite this variation, a trend can be seen in the comparative size of litters born to spotted and non-spotted parents (fig. 4). There is no diminution of litter size after the fourth litter for the parents without the chin spot trait, whereas those with the trait show a decline in litter size.

Many aspects of the productivity of white-spotted and non-spotted voles were compared in this study, and two major differences emerged. If both parents are white-spotted, fertility is lower than in unspotted crosses, while mixed crosses enjoy the highest fertility. Litter size declines after the fourth litter in spotted crosses, but there is no noticeable effect of parity on litter size in unspotted crosses in the laboratory (at least to litter no. 7). 
TABLE 5

Size of first four consecutive litters of white chin spot crosses*

\begin{tabular}{|c|c|c|c|c|c|c|c|c|c|}
\hline & & & & & & & & & \\
\hline & & 1st & & 2nd & & 3rd & & 4th & \\
\hline $\begin{array}{l}\text { Parental } \\
\text { type }\end{array}$ & No. & $\begin{array}{l}\text { Average } \\
\text { size }\end{array}$ & No. & $\begin{array}{l}\text { Average } \\
\text { size }\end{array}$ & No. & $\begin{array}{l}\text { Average } \\
\text { size }\end{array}$ & No. & $\begin{array}{l}\text { Average } \\
\text { size }\end{array}$ & Range \\
\hline $\mathrm{A} q \times \mathrm{A}^{w} \sigma$ & 8 & 4.75 & 7 & $4 \cdot 43$ & 5 & $5 \cdot 20$ & 4 & $4 \cdot 75$ & $1-8$ \\
\hline $\mathrm{A}^{w} q \times \mathrm{A}^{*}$ & 11 & 2.91 & 9 & 4.56 & 9 & $5 \cdot 33$ & 7 & $4 \cdot 14$ & $1-11$ \\
\hline $\mathrm{A}^{w} q \times \mathrm{A}^{w} \hat{\sigma}$ & 17 & $4 \cdot 18$ & 11 & $4 \cdot 45$ & 9 & $4 \cdot 89$ & 5 & $4 \cdot 60$ & 1.9 \\
\hline $\mathrm{A}^{w 0} \times \mathrm{B}^{*}$ & 10 & 3.80 & 7 & $4 \cdot 14$ & 7 & 3.00 & 6 & $3 \cdot 33$ & $1-9$ \\
\hline & $\overline{46}$ & $\overline{3.89}$ & $\overline{34}$ & $\overline{4 \cdot 41}$ & $\overline{30}$ & $\overline{4 \cdot 63}$ & $\overline{22}$ & $\overline{4 \cdot 14}$ & $\overline{1-11}$ \\
\hline
\end{tabular}

* Berkeley laboratory data.

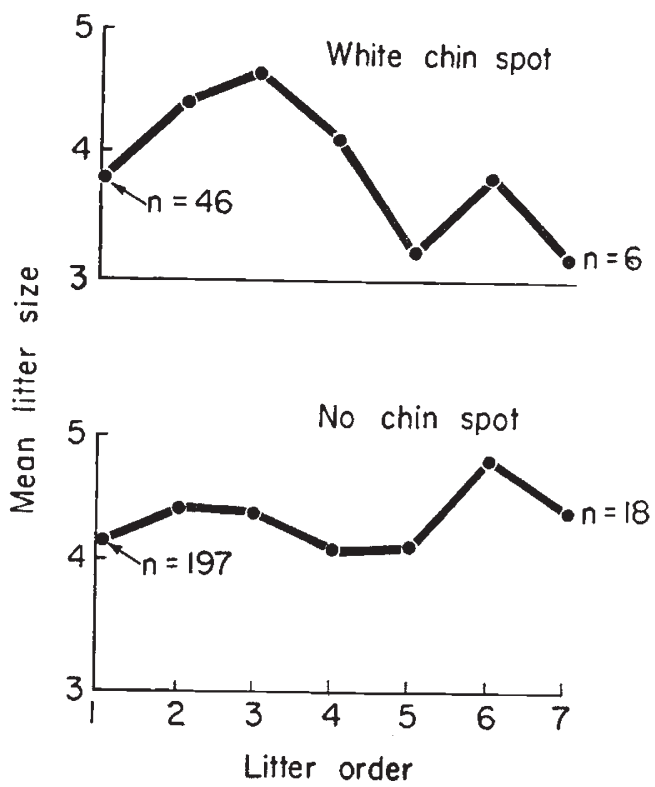

FIG. 4.-The effect of parity on litter size in white-spotted crosses and non-spotted crosses.

\section{(v) Sex ratios}

The sex ratios of spotted and non-spotted offspring born in whitespotting families were analysed to see if they followed the expected $1: 1$ ratio. Females with the white-spotting trait consistently produced more female offspring than male (table 6). The sex ratio of the combined offspring of the three $\mathrm{A}^{w}$ female crosses is $257 q: 211$, which differs from $1: 1$ at the 0.05 level. When only the male parent was white-spotted, males predominated among the offspring, but the ratio did not differ significantly from that expected. Due to these competing trends, the overall sex ratio in offspring of whitespotting families did not differ significantly from $1: 1$. 
The sex ratios of offspring produced in non-spotted crosses have also been analysed (Lidicker, 1963; Gill, 1972), and it was found that all crosses producing heterozygotes yielded a higher ratio of males. The sex ratio of $\mathrm{A} \times \mathrm{B}$ crosses was 190 \%:218 $\delta^{*}$. If this ratio is compared to that of $\mathrm{A}^{w} \times \mathrm{B}$ crosses $(58$ o $: 45 \hat{\sigma})$, it is seen that they are shifted in opposite directions, although the difference is only marginally significant $(0 \cdot 05<\mathrm{P}<0 \cdot 1)$. In the case of $\mathrm{A}^{w} \times \mathrm{B}$ crosses, effects associated with the white chin spot trait in females were apparently stronger than the tendency to produce an excess of male heterozygotes.

TABLE 6

Sex ratios of offspring from white chin spot crosses*

\begin{tabular}{|c|c|c|c|c|c|c|}
\hline \multirow{3}{*}{$\begin{array}{l}\text { Parental } \\
\text { type }\end{array}$} & \multicolumn{6}{|c|}{ Offspring } \\
\hline & \multicolumn{2}{|c|}{$\begin{array}{c}\text { Not } \\
\text { spotted }\end{array}$} & \multicolumn{2}{|c|}{ Spotted } & \multicolumn{2}{|c|}{ Total } \\
\hline & 우 & $\overrightarrow{0}$ & 우 & 0 & 우 & $\pi$ \\
\hline $\mathrm{A}$ 우 $\times \mathrm{A}^{w} \sigma^{*}$ & 26 & 46 & 25 & 25 & 51 & 71 \\
\hline $\mathrm{A}^{w} \phi \times \mathrm{A}_{\sigma}^{x}$ & 56 & 58 & 42 & 25 & 98 & 83 \\
\hline $\mathrm{A}^{w} 0 \times \mathrm{A}^{w} \sigma^{\tau}$ & 38 & 24 & 63 & 59 & 101 & 83 \\
\hline \multirow[t]{2}{*}{$\mathrm{A}^{w} \phi \times \mathrm{B}_{0}^{\pi}$} & 54 & 39 & 4 & 6 & 58 & 45 \\
\hline & 176 & 167 & 134 & 115 & 308 & 282 \\
\hline
\end{tabular}

\section{Discussion}

There is a diversity of white spotting traits found in mammals, and their modes of inheritance are equally diverse, including single recessive or dominant genes, multiple allelic loci and multifactorial inheritance (Searle, 1968). Some have serious pleiotropic effects and others, such as belted (bt) in house mice and white star in deer mice do not. The pleiotropic effects of white spotting are associated with the site of action of the mutation. There are two major sites of gene action in white spotting-the neural crest, from which melanoblasts develop, and the local cellular environments through which the melanoblasts migrate and, upon reaching their destination, differentiate into pigment-bearing melanocytes. Dominant spotting $(W)$, piebald $(s)$, splotch $(S p)$ and patch $(P h)$ are neural crest mutants in the house mouse, and they all lack melanocytes in the white spots (Deol, 1970). They also suffer serious pleiotropic effects traceable to defects in other tissues of neural crest origin: megacolon in piebald mice (Bielschowsky and Schofield, 1962), anaemia in dominant spotting mutants and sterility of its homozygotes (Mayer and Green, 1968), lethality in splotch (Auerbach, 1954) and patch homozygotes (Grüneberg and Truslove, 1960).

The environments through which the melanoblasts must migrate may affect their multiplication and distribution. Schaible (1963, cited in Searle, 1968) has described two medial and six bilateral centres on the mouse's dorsal coat from which pigment spreads. Areas furthest from the centres, such as the mid-ventral region, tail tips and feet, may remain unpigmented if the melanoblasts are slowed by local cellular environments along the way.

Mintz (1971) has conducted a more detailed analysis of the origin of coat 
colour pigmentation. She studied colour pattern development in " allophenic" mice derived by fusing two cleavage-stage embryos in vitro and transplanting the mosaic blastocyst to a pseudopregnant mother. By combining embryos with different genetic markers for coat colour and observing the resultant coat pattern in the mosaic individual produced, Mintz determined that 34 clones of melanoblasts are present, 17 on each side of the animal, including the tail. In a similar manner, she found that there are approximately 170 independently arising clones of hair follicle cells. She postulated that the physical overlap of the melanoblast clones with the hair follicle clones give rise to the variety of coat colour patterns observed in mice.

The local environment in which melanoblasts differentiate into melanocytes may also be the site of action of white-spotting genes. Mayer and Green (1968) showed that spotting controlled by the steel locus $(S l)$ in mice is due to a defect in the skin and not in the melanoblasts themselves. In the belted mutation ( $b t)$, hair follicles in the spotted areas prevent the differentiation of melanoblasts. Pleiotropic effects have been found for some of the mutants affecting local environments and not for others (Searle, 1968).

In the house mouse, at least 10 loci with two to eight known alleles per locus are concerned with white spotting (Deol, 1970). Genes homologous to dominant $(W)$ and piebald $(s)$ spotting have been found in one vole species, Microtus arvalis (Frank and Zimmerman, 1957, cited in Searle, 1968). Some types of spotting appear to be multifactorial. Breeding data for white star (a white patch on the top of the head and sometimes ventrally) suggested multifactorial inheritance in the deer mouse (Barto and Huestis, 1933). Modifying genes may strongly influence the phenotypic expression of white spotting (Little, 1958).

The breeding data presented in this paper show that white spotting in Microtus californicus does not follow a simple Mendelian segregation pattern and is not controlled at a single locus. It differs from most neural crest mutations in that it is not controlled by a major gene and does not have pleiotropic effects causing serious physical defect or loss of viability. Of the known white spotting mutants described in the literature, the trait in the California vole is closest to white star in deer mice (Barto and Huestis, 1933). The site of gene action is more likely the local environment than the neural crest. It may be that defects of local environments along the way slow the migration of the melanoblasts so they do not reach the ventral sites, or that the site at which the melanoblasts differentiate and enter the hair follicles is affected.

Many possible models of inheritance have been examined for agreement with the data and none has been found satisfactory. Multifactorial inheritance of a non-additive nature, involving a threshold and epistatic interactions seems to be the most plausible model remaining. The trait is similar in expression to quasi-continuous skeletal variables with various degrees of severity studied by Grüneberg (1952). He suggested the existence of underlying (and unidentified) continuous variables which at critical values lead to the expression of quasi-continuous variables. My data suggests a threshold for the expression of white spotting and an underlying continuous distribution, since spotting is graded and never extends to the chest unless the chin is also spotted. Both the incidence of large spots in M. c. californicus and the extension of spotting in $M$. c. stephensi increase when inheritance of spotting 
factors is from both parents and when there are more severe forms of spotting in the parents (fig. 2). Some of the same loci appear basic to white spotting in both subspecies, but additional loci or modifying genes probably lead to the extension of the white spot to the chest in stephensi. The expression of extended and disjunct spots is not impaired in hybrid offspring of stephensi $\times$ californicus, even though they do not occur in californicus.

Variability for white spotting was hidden to some extent in the natural populations of California voles sampled, especially on the mainland. The incidence was highest among Brooks Island voles, $7 \cdot 6$ per cent, although the buff allele which is shown in the study to hinder the expression of white spotting also occurs at higher frequency on the island (Gill, 1972). The incidence of white spotting is greatly reduced in the presence of buff alleles, but not completely suppressed (fig. 2). Epistatic interactions of coat colour genes are not uncommon in mammals (Searle, 1968). In this case the epistatic effect of the buff allele is to raise the threshold for the expression of white spotting. The mechanism of the interaction is not known.

Deol (1970) has commented on the surprisingly low number of coatcolour polymorphisms observed in wild mammalian populations, considering the large number of loci involved and the relatively high mutation rates. He suggested that the low incidence of polymorphisms may be due to predation or deleterious pleiotropic effects. In this study, polymorphism exists in all populations investigated, but it is largely hidden. Some form of selection may be operating against white-spotted individuals in natural populations, for the incidence of spotting was higher in their laboratory-born progeny than in field-trapped voles from mainland populations. Voles are subject to heavy predation on the mainland (Pearson, 1964, 1971; Stendell and Myers, 1973), but not on Brooks Island (Lidicker and Anderson, 1962). White spotting seems to be more prevalent on Brooks Island than the mainland, so the possibility of selection through predation on the mainland should be considered. Still, the likelihood of differential predation against white-spotted voles does not seem high, since the spots are ventral and not obvious.

Pleiotropic effects associated with reproduction were found in this study. Fertility differed significantly among crosses. It was 88 per cent when only one parent was spotted, 52 per cent when both were, and 70 per cent if neither were. The higher fertility of crosses in which one parent is spotted would tend to increase the incidence of white spotting. Low fertility of crosses in which both parents are spotted and decrease in litter size after the fourth litter in crosses in which one or both parents are spotted (fig. 4) would tend to decrease it. Considering the relatively low frequency of the trait in natural populations, a white-spotted individual has a much lower probability of mating with another spotted vole than with an unspotted one. Therefore the higher fertility of crosses in which one parent is spotted would be the predominant effect and would tend to maintain white spotting genes in natural populations. A decline of litter size after the fourth litter may not at first seem to be important in the wild, since life expectancy is lower than in the laboratory and a female is not likely to produce four or more litters. If, however, the decline in litter size occurs earlier in the wild, just as ageing is accelerated, the relative proportion of white-spotted individuals could be reduced in this way.

White-spotted females tended to produce fewer young in this study 
(table 4) and, although this was not a significant difference, it would be enhanced by the sex ratio favouring female progeny in crosses of whitespotted mothers (table 6). It is interesting that neither productivity nor fertility is correlated with spot size per se. Presence or absence of the spot is important, but not the size. This suggests that the threshold for expression of white spotting is high and the differences among spotted variants is not great.

Acknowledgements.-Part of this research was conducted while the author was the recipient of a National Institute of Health Training Grant, awarded by the Department of Genetics at the University of California, Berkeley. Financial assistance at UCLA was provided by a USPHS Biomedical Science Support Grant. I would like to thank M. A. Spence for consultation on the computer programs used in this analysis. My appreciation goes to W. Z. Lidicker, Jr. and K. L. Lange for reading the manuscript. Computing assistance was obtained from the Health Sciences Computing Facility, UCLA, supported by NIH Special Resources Grant RR-3.

\section{REFERENCES}

AUERBACH, R. 1954. Analysis of the developmental aspects of a lethal mutation in the house mouse. 7. Exp. Zool., 127, 305-329.

BARTO, E., AND HUESTIS, R. R. 1933. Inheritance of white star in the deer mouse. F. Hered., $24,245-248$.

berry, R. J., AND southern, H. N., Eds. 1970. Variation in Mammalian Populations. Symp. Zool. Soc. Lond., No. 26, 403 pp. Academic Press.

BIELSGHOWSKY, м., AND SGHOFIELD, G. c. 1962. Studies on megacolon in piebald mice Aust. F. Exp. Biol. Med. Sci., 40, 395-404.

DEOL, M. S. 1970. The determination and distribution of coat colour variation in the house mouse. Symp. Zool. Soc. Lond., No. 26, 239-250.

falconer, D. s. 1960 . Introduction to Quantitative Genetics. The Ronald Press Co., N.Y. $365 \mathrm{pp}$.

FALCONER, D. s. 1965. The inheritance of liability to certain diseases, estimated from the incidence among relatives. Ann. Hum. Genet., Lond., 29, 51-77.

FRANK, F., AND ZIMMERMAN, K. 1957. Farbungs-Mutationen der Feldmaus. Z. Saugetierk., $22,87-100$.

GILL, A. E. 1972. Maintenance of a coat-coler polymorphism in an island population of the California vole. Ph.D. Thesis, Univ. California, Berkeley, Calif. 171 pp.

GRÜNEBERG, H. 1952. Genetical studies on the skeleton of the mouse-IV. Quasicontinuous variations. F. Genet., 51, 95-114.

GRÜNEBERG, H., AND Truslove, G. M. 1960. Two closely linked genes in the mouse. Genet. Res. Camb., 1, 69-90.

LIDICKER, w. z., JR. 1963. The genetics of a naturally occurring coat-color mutation in the California vole. Evolution, 17, 340-346.

LIDICKER, w. Z., JR., AND ANDERSON, P. K. 1962. Colonization of an island by Microtus californicus, analysed on the basis of runway transects. F. An. Ecol., 31, 503-517.

uITTLE, c. c. 1958. Coat color genes in rodents and carnivores. The Quarterly Rev. Biol., 33, No. 2, 103-136.

MAYER, T. C., AND GREEN, M. C. 1968. An experimental analysis of the pigment defect caused by mutations at the $W$ and $S l$ loci in mice. Devel. Biol., 18, 62-75.

mintz, B. 1971. Clonal basis of mammalian differentiation. Symp. Soc. Exp. Biol., 25, 345-370.

OWEN, R. D., AND SHAGKELFORD, R. M. 1942. Color aberrations in Microtus and Pitymys. F. Mammal., 23, 306-314.

PEARSON, O. P. 1964. Carnivore-mouse predation: an example of its intensity and bioenergetics. F. Mammal., 45, 177-188.

PEARSON, O. P. 1971. Additional measurements of the impact of carnivores on California voles (Microtus californicus). 7. Mammal., 52, 41-49.

QUEVEDO, w. C., JR. 1971. Genetic regulation of pigmentation in mammals. In Biology of Normal and Abnormal Melanocytes, ed. T. Kawamura, T. B. Fitzpatrick, and M. Seiji, pp. 99-115. Univ. of Tokyo Press, Tokyo. 
REICH, T., JAMEs, J. W., AND MORRIs, C. A. 1972. The use of multiple thresholds in determining the mode of transmission of semi-continuous traits. Ann. Hum. Genet., Lond., 36, 163-183.

ROBINsON, R. 1970. Homologous mutants in mammalian coat colour variation. Symp. Zool. Soc. Lond., No. 26, 251-269.

scharble, R. J. 1963. Developmental genetics of spotting patterns in the mouse. Ph.D. Thesis, Iowa State Univ., Ames, Iowa.

searle, A. G. 1968. Comparative Genetics of Coat Colour in Mammals. Logos Press, London. 308 pp.

SOKAL, R. R., AND ROHLF, F. K. 1969. Biometry. W. H. Freeman, S. F. 776 pp.

STENDELL, R. C., AND MYERS, P. 1973. White-tailed kite predation on a fluctuating vole population. The Condor, 75, No. 3, 359-360.

STODDART, D. M. 1970. Tail tip and other albinisms in voles of the genus Arvicola Lacépède 1799. Symp. Zool. Soc. Lond., No. 26, 271-282. 